\title{
Characterization of a dance movement using a Kinetic camera*
}

\author{
Inês C.J. Barbosa, João Milho, Inês M. Lourenço, Ana Mota, Vanda S. Nascimento, André D. \\ Carvalho, Ricardo F. Portal, Alda N. Carvalho
}

\begin{abstract}
Dance is an art form considered as a form of language since it can sometimes reflect a culture of a population or even a celebration that accompanies humanity from its earliest times and which requires of the dancer a high physical and emotional dexterity. However, it is expected that the dancer performs rigorous and repetitive technical movements that often lead to painful injuries.

Due to the high number of injuries, it is essential to study and analyze base movements for this type of dance in order to prevent injuries and to optimize the dancer's choreography and productivity. These movements are precedents of more complex movements. In this work, the study of a basic jump, the Grand Jeté, using biomechanical techniques is carried out by finding the kinematics of the movement.

For the data collection, three dancers ( 2 females and 1 male) voluntarily participated and the movements were capture using a 2nd Generation Kinect camera that allows the capture of 3D movement. The biomechanical analysis was performed for the movement recorded and the results were presented to show the adequacy of the methodology proposed. By using this methodology, the aim is to characterize the movement and to be able to promote a better understanding of everything involved in the performance of the movement with the performers and teachers.
\end{abstract}

\section{INTRODUCTION}

Dance is an art form considered as one of the most important forms of language, sometimes reflecting the culture of a population and accompanying humanity from its earliest times [1]. In the sixteenth century, the Classical Ballet emerges in France, which marks the Renaissance period and leads its practitioners to acquire demanding physical and emotional skills. Over time, these abilities have revealed certain damaging aspects since they can lead to painful injuries for the dancers. A study concluded that $56 \%$ of the Classical Ballet dancers would suffer from some type of injury muscle-skeletal muscle [2].

*Research supported by Instituto Politécnico de Lisboa through Project EBME (IPL/2017/EBME/ISEL).

Inês C.J. Barbosa, João Milho, Inês M. Lourenço, Ana Mota, Alda N. Carvalho, André D. Carvalho, Ricardo F. Portal are with GIMOSM - Grupo de Investigação em Modelação e Optimização de Sistemas Multifuncionais, ISEL - Instituto Superior de Engenharia de Lisboa, Av. Conselheiro Emídio Navarro 1, 1959-007 Lisboa, Portugal. (00-351-218-317-000; fax: 00-351218-317-213; e-mail: ines.barbosa@dem.isel.ipl.pt).

Vanda S. Nascimento is with Escola Superior de Dança, Av. Conselheiro Emídio Navarro 1, 1959-007 Lisboa, Portugal.

Inês C.J. Barbosa, João Milho, André D. Carvalho, Ricardo F. Portal with LAETA, IDMEC - Instituto Superior Técnico, Universidade de Lisboa, Av. Rovisco Pais 1, 1049-001 Lisboa, Portugal.
Due to the high number of injuries, using Biomechanics in the study and analysis of base movements that are precedents of more complex movements in this type of dance may provide relevant information in order to prevent injuries and to optimize the dancer's productivity.

Biomechanics allows obtaining information on quantitative measures that are sometimes not easy to observe from the qualitative point of view. Thus, using kinematics, it is possible to describe the movement in terms of its height, speed and its distance from an initial reference of an anatomical segment intended for study and to perceive which instances of the movement are essential for its success, or, on the contrary, by the negative influence on injuries and also on performance. Using motion kinetics, it is possible to conclude what external forces (related to the external environment surrounding the dancer) are produced, as well as the internal forces of motion, related to muscles and bones and thus dependent on the individual characteristics of the participant.

To perform such an analysis, it is necessary that the movement in study is previously recorded in such a way that the relevant information regarding the body in movement is obtainable. To obtain a three-dimensional reconstruction of the movement in study, usually several cameras are used in such an orientation that all the relevant point on the body are present in the recording. However, nowadays a single camera can be used if it also uses an infrared sensor and an infrared light emitter. The Kinect sensor was developed by Microsoft Company as an accessory to XBOX 360 [3]. It was launched in 2010 and its main function is facial recognition and the ability to recognize the user's joints [4]. The Kinetic sensor combines the high definition images with the information from the infrared sensor and emitter to obtain the depth of the space where the object moves [5]. Thus, it is possible to reconstruct a movement in three dimensions.

The main objective of this work is to use a Kinetic sensor to obtain the characterization of a Grand Jéte, a movement typical of the Classical Ballet.

\section{METHODS}

\section{A. Selection of the movement}

Ballet is considered technically complex, since it requires demanding principles of training and physiology, and in order to the development of a safe technique, biomechanical laws should be considered. Each movement must therefore be studied in detail from the beginning of the movement to its completion [6].

In order to understand each movement the following progression must be taken into account: each movement of 
the arm is constructed from a basic position of arms and each movement of the leg is developed from one of the five fundamental positions of the feet. It is the combination of these movements and positions that leads to the variety of movements characteristics of Ballet [6].

The jumps in the Classical Ballet are of most importance in terms of biomechanical analysis, not only for their repetition that sometimes leads to the appearance of associated injuries, but also for the magnitudes of forces that are produced that can surpass in a large scale the body mass of the subject [6].

Jumps are movements that require the professionals to have extreme joint amplitudes and large muscular capabilities that result in mechanical stress in the soft tissues and adjacent bones. This is reflected in ligament and joint lesions that occur more frequently in the lower limb [6].

To perform a jump in the Ballet there are always three associated components: the Ballon, which is related to the resistance of the jump actions; the turn-out, described as the maximum external rotation of the leg in relation to the hip joint; and finally, the demi-plié, which results from a semiflexion of the knees with the heels on the ground. The jump is then the result of a combination of force and elasticity in order to facilitate the impulsion and reception with respect to the ground [6].

The Grand Jeté is one of the basic jumps in the Classical Ballet where the jumper elevates one leg in the air, jumps into the air by pushing the other leg from the ground and lands with the leg that was first elevated from the ground [6]. It is one of the first jumps introduced to the beginner dancer.

\section{B. Participants}

For the realization of the study, three participants, students of the School of Dance of the Polytechnic Institute of Lisbon, performed the Ballet movement. The requirements for the selection of the participants were defined as:

- Age between 18-21 years old

- $\quad$ Practitioners of artistic dance for at least 5 years

The characteristics of the participants are presented in Table I.

\section{Movement Capture}

The Microsoft Kinect sensor was developed as an accessory to the Xbox 360 with the goal of making the most appealing and interactive gaming experience [3]. It was launched in 2010 and consists of an RBG color camera, infrared sensor, an infrared light emitter and four microphones, since it also allows voice recognition, and in its main functions are the ability to recognize joints of its user and facial recognition [4]. The introduction of the infrared sensors and emitters permitted to establish a relationship between a point of the image collected and its distance from the sensor, thus providing coordinates in three-dimensional space (introduction of the $\mathrm{Z}$ coordinate in relation to the $\mathrm{X}$ and $\mathrm{Y}$-coordinates already achieved with RGB camera) $[3,4]$.
TABLE I. CHARACTERISTICS OF THE PARTICIPANTS IN THE STUDY

\begin{tabular}{|c|c|c|c|c|}
\hline Participant & Gender & $\begin{array}{c}\text { Height } \\
{[\mathbf{m}]}\end{array}$ & $\begin{array}{c}\text { Weight } \\
{[\mathbf{k g}]}\end{array}$ & $\begin{array}{c}\text { Shoe Size } \\
{[\text { EU size] }}\end{array}$ \\
\hline 1 & Female & 1,60 & 59 & 36 \\
\hline 2 & Female & 1,63 & 55 & 37 \\
\hline 3 & Male & 1,77 & 70 & 43 \\
\hline
\end{tabular}

The participants performed the jump in study and the movement was captured by using the Kinetic sensor and the iPi Recorder software [7]. To analyze the movement, a specialized software was used, iPi Mocap Studio [8] and its Biomech Add-On [9]. With this software it is possible to obtain graphics of position, velocity and acceleration over time for the movement.

\section{RESULTS}

Considering that the Grand Jeté is a basic jump in the Classical Ballet and that besides the legs also the arms and the torso and head are contributing to the jump, the biomechanical analysis was performed to the whole body. The results presented in this work focus on the movement analysis of the lower extremity and correspond to the movement performed by the male participant. To study the lower extremity movement, the movement of the foot, tibia, and femur were considered.

\section{A. Position Analysis}

In terms of the position analysis of the components of the leg, Figs. 1 (a) and (b) show the $x$ - and y-coordinates of the right foot over time, respectively. This is the foot that starts the movement, elevating from the ground.

It can be observed there is a little variation in the movement on the $\mathrm{x}$-coordinate axis. There is a variation of about $10 \mathrm{~cm}$ of the right foot in its ascending phase and a similar variation in the descending phase. In regards to the ycoordinate, the depth, it can be observed a polynomic progression of the position of the foot during the jump. In the leg raising phase of the movement, the foot reaches a maximum variation of $139 \mathrm{~cm}$.

Figure 1. Movement of the right foot (a) $x$-coordinate (b) y-coordinate (c) z-coordinate

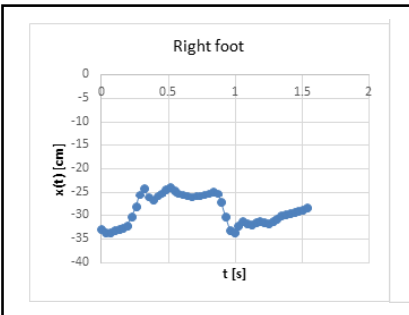

(a)

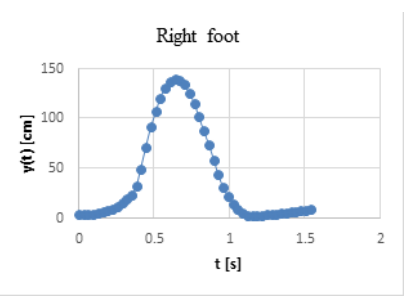

(b)

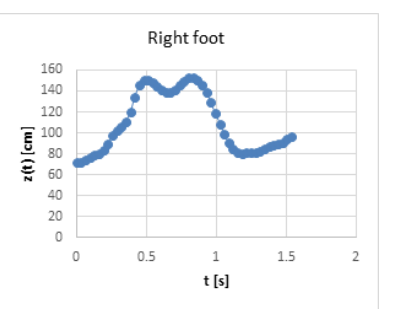

(c) 


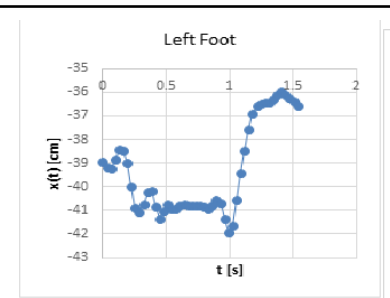

(a)

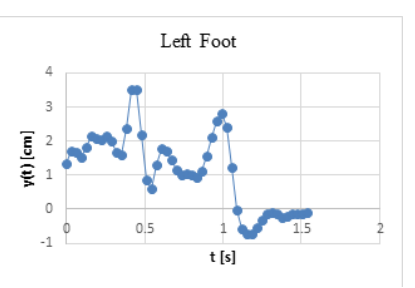

(b)

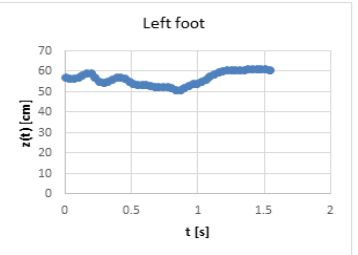

(c)

Figure 2. Movement of the left foot (a) x-coordinate (b) y-coordinate (c) zcoordinate

The elevation of the right foot can be observed in Fig. 1 (c), where the foot reached a maximum height of $152 \mathrm{~cm}$ and occurs at $\mathrm{t}=0.86 \mathrm{~s}$.

The movement of the left foot can be observed in Fig. 2. As this is the second foot to leave the ground and its function is to support and stabilize the jump, it can be observed that there are small variations in all the coordinates.

The right femur has a variation of position that is less than $10 \mathrm{~cm}$ in the $\mathrm{x}$-coordinate, Fig. 3(a). It is possible to observe that it does not have a large movement in the $y$ coordinate, Fig. 3(b).

In terms of the elevation, Fig. 3 (c), the right femur follows the movement of the leg but it has its highest point before the position of the most elevations of the leg $(\mathrm{t}=0.86$ s).

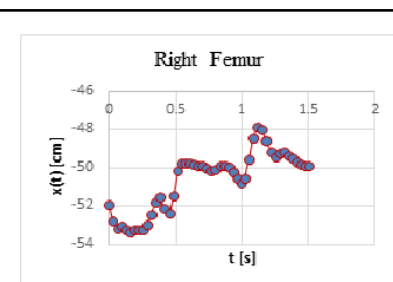

(a)

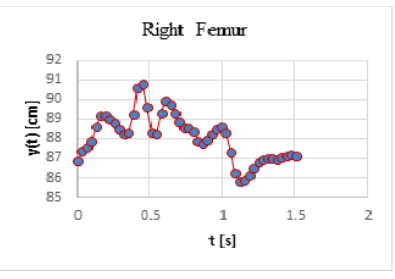

(b)

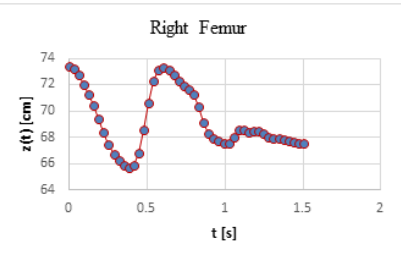

(c)

Figure 3. Movement of the right femur (a) $x$-coordinate (b) y-coordinate (c) z-coordinate

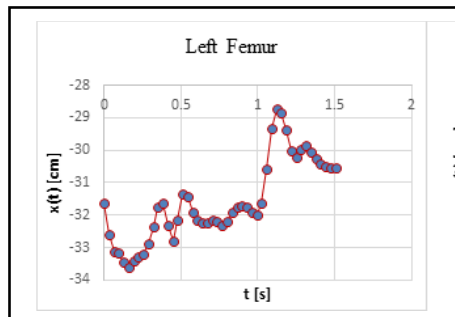

(a)



(b)

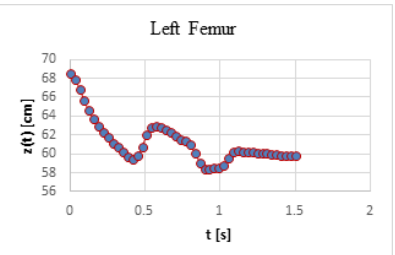

(c)

Figure 4. Movement of the left femur (a) x-coordinate (b) y-coordinate (c) $\mathrm{z}$-coordinate

Figs. 4 (a) and (b) show that the left femur was very much in the same position all time of the analysis. This is the support leg of the jump so it is supposed to move less than the other leg and it can be observed that only in the $\mathrm{z}$ coordinate, Fig. 4 (c), there is relevant variation of the position of the left femur.

\section{B. Velocity Analysis}

The lower extremity was also studied in terms of the velocity of the femur and the tibia of the right leg.

The velocity of the right femur in the $\mathrm{x}$ - coordinate, shown in Fig. 5(a), is variable between $-18 \mathrm{~cm} / \mathrm{s}$ and $36 \mathrm{~cm} / \mathrm{s}$.

The same behavior can be observed in Fig. 5(b) where the variation is between $-36.95 \mathrm{~cm} / \mathrm{s}$ to $37.94 \mathrm{~cm} / \mathrm{s}$.

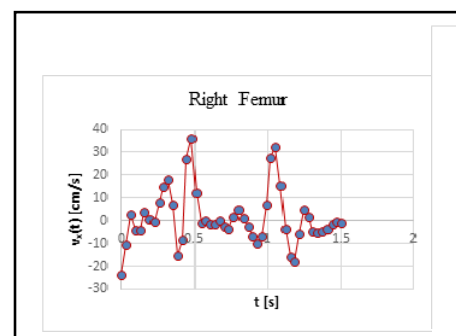

(a)

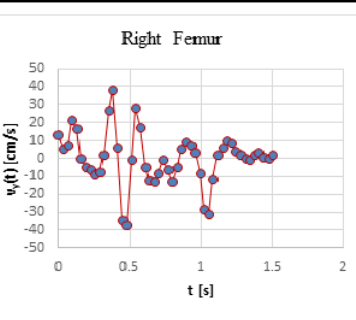

(b)

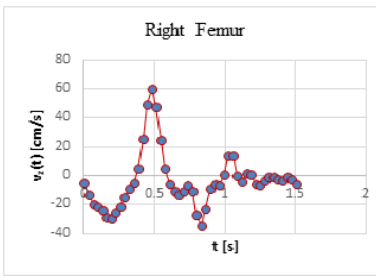

(c)

Figure 5. Velocity of the right femur (a) x-coordinate (b) y-coordinate (c) $\mathrm{z}$-coordinate 


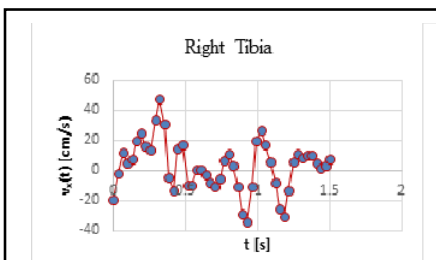

(a)



(b)

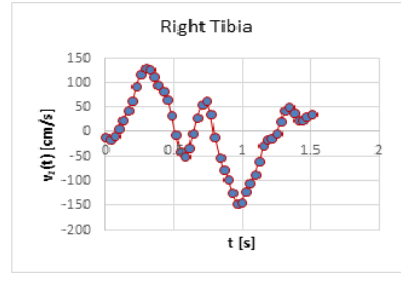

(c)

Figure 6. Velocity of the right tibia (a) $x$-coordinate (b) y-coordinate (c) $z$-coordinate

Fig. 5 (c) shows the velocity profile for the right femur in the z-coordinate. It is possible to observe that the velocity decreases when the jump is initiated and then it increases and decreases again, ending with no velocity. This corresponds to the part of the jump where the femur almost does not change its position.

Because the right leg is the leg with the most amplitude of movement, when the velocity profile of the right tibia is taken, it is observed that the velocity in the x-coordinate, shown in Fig. 6(a), is smaller when compared to the other coordinates. In Fig. 6(b), it can be observed that the right tibia suffers a velocity that increases during the elevation of the leg up to $241.7 \mathrm{~cm} / \mathrm{s}$, and decreases in the stabilization of the jump to $-215.3 \mathrm{~cm} / \mathrm{s}$. The tibia presents almost no movement when the jump is ending as the right leg touches the ground. The velocity in the z-coordinate, shown in Fig. $6(\mathrm{c})$, also presents an oscillating progression between -145.9 $\mathrm{cm} / \mathrm{s}$ e $129.1 \mathrm{~cm} / \mathrm{s}$.

\section{CONCLUSION}

The main objective of this work was to characterize a basic jump of the Classical Ballet by using biomechanical analysis of the movement.

The movement studied was the Grand Jeté, a basic jump introduced to beginner dance students. Three dancers, two females and one male, where asked to perform the jump in front of a Kinetic sensor that together with recorder software from IPIsoft, allowed for the capture of the movement.

The movement was then analyzed and some results were presented. It was shown that it is possible to obtain the position and velocity profiles for different members of the body. These permit information regarding the different stages of the jump.

The analysis of the different members should be completed and a way to give information regarding a correct and beautiful jump should be devised.
Also, it would be important to identify the critical moments of the jump in terms of injuries and find appropriate information to provide to performers, teachers and chorographers in order to avoid such problems.

\section{REFERENCES}

[1] L. C.Schweich, A. M. Gimelli, M. B. Elosta, W. S. W. Matos, P. F. Martinez, S. A. Oliveira Jr, "Epidemiology of athletic injuries in classic ballet practitioners", in Fisioterapia e Pesquisa, vol. 21, no. 4, pp. 353-358, Dec 2014. ISSN 1809-2950

[2] E.R. Wiesler, D.M. Hunter, D.F. Martin, W.W. Curl, H. Hoen, “Ankle Flexibility and Injury Patterns in Dancers", Am J Sports Med, vol. 24, no. 6, pp. 754-757, Nov-Dec1996. doi: 10.1177/036354659602400609

[3] D. Pagliari, L. Pinto, "Calibration of Kinect for Xbox One and Comparison between the Two Generations of Microsoft Sensors", Sensors (Basel), vol. 15, no. 11, pp. 27569-27589, Oct 2015. doi: 10.3390/s151127569.

[4] J. Bento, A.P. Cláudio, P. Urbano, "Avatares em língua gestual portuguesa", in Proc. 9th Iberian Conference on Information Systems and Technologies, Barcelona, Spain, June 2014, pp 185-191.

[5] K. Khoshelham,"Accuracy Analysis of Kinect Depth Data", International Archives of the Photogrammetry, Remote Sensing and Spatial Information Sciences, Volume XXXVIII-5/W12, 2011.

[6] A. S. M. A. Dias, "Descrição Biomecânica de Saltos Específicos do Ballet Clássico: Determinação da Influência de Movimentos que Antecedem os Saltos com Contra Movimento", MSc Thesis, Universidade do Porto, 2009.

[7] iPi Recorder, iPi Soft LLC. Moscow. http://www.ipisoft.com

[8] iPi Mocap Studio, iPi Soft LLC. Moscow. http://www.ipisoft.com

[9] Biomech Ad-on for iPi Mocap Studio, iPi Soft LLC. Moscow. http://www.ipisoft.com 